\title{
Construção da Escala Todaro: atitudes de crianças em relação a idosos
}

\author{
Mônica de Ávila Todaro*
}

\begin{abstract}
Resumo
O objetivo deste estudo foi levantar significados de velhice entre as crianças e representá-los estruturadamente nos moldes de uma escala diferencial semântica, facilmente inteligível para elas. Escalas são meios de avaliação psicológica em que o respondente atribui graus de intensidade a elementos postos à sua análise. Sabe-se que as atitudes podem ser inferidas apenas por evidências de respostas ou indicadores. O método escalar tem ampla aceitação na Psicologia, na pesquisa e na intervenção. Pretende-se descrever a construção da Escala Todaro, para a avaliação de atitudes de crianças em relação a idosos e, despretensiosamente, iniciar um processo de colaboração com os pesquisadores e educadores engajados numa visão progressista de ensino. A Pedagogia Progressista é, no Brasil, um paradigma que propõe a transformação social por meio da educação.

Palavras-chave: Atitudes; Crianças; Idosos; Educação.
\end{abstract}

\section{Todaro’s Scale construction: Children's attitudes towards the elderly}

\begin{abstract}
The aim of this study was to raise meanings of old age among children and represent them structurally along the lines of a semantic differential scale, easily intelligible to them. Scales are psychological evaluation resources that the respondent assigns degrees of intensity to the elements placed at their analysis. It is known that attitudes can be inferred only by evidence of answers or indicators. The scalar method has wide acceptance in psychology, research and intervention. We intend to describe the construction of Todaro's Scale for assessing children's attitudes toward elderly and unpretentiously, start a process of collaboration with researchers and educators engaged in a progressive vision of education. The Progressive Education is, in Brazil, a paradigm that proposes social transformation through education.

Keywords: Attitudes; Children; Elderly; Education.
\end{abstract}

\section{Introdução}

Escalas são instrumentos de avaliação psicológica em que o respondente atribui pesos ou graus de intensidade a elementos que lhe são oferecidos para julgar, os quais lhe são apresentados sob a forma de uma sequência de itens escolhidos com base em uma teoria e em pesquisa empírica. Foi essa forma simples a encontrada por Louis L. Thurstone, o criador das primeiras escalas psicológicas, para definir instrumentos de medida cujo uso começou nos campos da inteligência, da personalidade e das atitudes e que se expandiu para todas as áreas da psicologia (THURSTONE, 1976). O raciocínio subjacente era que assim como é possível medir eventos físicos e psicofísicos, comparando-os com uma medida graduada padronizada, fenômenos psicológicos também seriam passíveis de medida.

Atitudes não são diretamente observáveis. Sua existência pode ser inferida apenas por evidências de respostas ou indicadores. Segundo Eagly e Chaiken (1993), foi em 1946 que um dos fundadores da teoria moderna de medição ou mensuração, S. S. Stevens, definiu o termo como a indicação de números de objetos ou eventos de acordo com certas regras que reflitam as relações entre número e atributo a ser medido. As autoras afirmam que para medir é necessário: 1) definir o que será medido; 2) definir o critério para a medição (escala); 3) ler os resultados e 4) interpretar os dados. $\mathrm{O}$ problema central da medida consiste em justificar a legitimidade de se passar de procedimentos e operações empíricas para uma representação numérica destes procedimentos. A confiabilidade e a validade de um instrumento de medida implicam no quanto o instrumento é consistente sobre repetidas observações e também na consistência de resultados obtidos pelos mesmos sujeitos em diferentes ocasiões ou com diferentes conjuntos de itens equivalentes (EAGLY; CHAIKEN, 1993).

Likert (1976) introduziu uma variação na forma de apresentação dos itens de escalas de atitudes proposta por Thurstone. Considerando a grande dificuldade inerente à seleção de uma ampla gama de itens de natureza avaliativa, ele propôs que fosse estruturado um conjunto básico de itens contendo juízos de valor com relação a um dado objeto, itens esses que deveriam ser analisados um a

\footnotetext{
*Endereço Eletrônico: mavilatodaro@ufsj.edu.br
} 
um pelos respondentes. Estes deveriam assinalar sua escolha em escalas que percorrem um contínuo da maior concordância à maior discordância (concordo totalmente, concordo, em dúvida, discordo e discordo totalmente). Ou seja, o que está em jogo não é a intensidade, mas a qualidade de cada resposta. O resultado final de uma escala desse tipo é dado pela somatória das respostas de concordância, discordância ou neutralidade e pela análise da concordância interna das concordâncias versus as discordâncias na escala total.

O método escalar ganhou ampla aceitação em praticamente todas as áreas da Psicologia. Hoje em dia não só é de uso corrente na pesquisa e na intervenção, como a literatura crítica e metodológica sobre ele é abundante. Como requisitos essenciais para a construção de uma escala podem ser citados: 1) a presença de uma teoria que dê sustentação à medida; 2) uma noção clara sobre a natureza do construto a ser avaliado, estabelecendo seu caráter unidimensional ou multidimensional; 3) definições constitutivas dos construtos, de natureza abstrata, feitas segundo a teoria; 4) definições operacionais dos construtos, que especificam os comportamentos observáveis a eles correspondentes e como serão medidos; 5) operacionalização dos construtos, ou construção dos itens que o representam; 6) análise teórica dos itens, que se subdivide em análise semântica e análise de conteúdo, lógica ou de construto e é feita por juízes especialistas; 7) análises de confiabilidade (com as modalidades: entre diferentes avaliadores, testereteste e de confiabilidade interna dos itens), e 8) análises de validade - de conteúdo, de critério e de construção (PASQUALI, 1999).

Além das escalas tipo Thurstone \& Likert, uma outra modalidade de medida escalar se fez presente no campo da avaliação psicológica. Tratase do diferencial semântico, concebido por Osgood, Suci e Tannembaun (1976) para avaliar atitudes, que eles definem como respostas implícitas ou estados inferidos do organismo, aprendidos e que funcionam como predisposições para o comportamento, ou como mediadores entre o estímulo e a resposta. Para os autores, o que distingue as atitudes de outros estados internos que funcionam como predisposições (exemplos: motivos e metas), é seu caráter avaliativo, que se traduz em tendências de aproximação e esquiva ou de aceitação e rejeição. São representadas por um continuo básico bipolar com um ponto de referência neutro ou zero, o que implica que têm direção e intensidade. Dessa forma, a medida de atitude em relação a um dado objeto social, consiste em submeter um indivíduo à tarefa de assinalar um ponto em sucessivas escalas bipolares ancoradas por adjetivos antônimos, conforme o grau em que acredita que eles representam sua avaliação desse objeto social. As escalas medem a direção da atitude, conforme se orientem à esquerda ou à direita da reta que as representa (ex: saudável $\mathrm{x}$ doente; feio x bonito). Medem também a força ou intensidade da resposta avaliativa, indicada pela distância entre o ponto assinalado em relação à origem. Os pares de adjetivos que ancoram as escalas bipolares são definidos por pesquisa prévia em que são levantados os adjetivos mais comumente utilizados por uma comunidade verbal para referir-se a um dado objeto social.

Algumas considerações metodológicas básicas correspondem à avaliação do aspecto afetivo-avaliativo das atitudes mediante o diferencial semântico: 1) uma escala diferencial semântica deve conter um conjunto de adjetivos bipolares, que devem ser adequados à idade e à cultura do respondente; 2) os resultados tendem a correlacionar-se e a maior parte de sua covariância se explica por três dimensões básicas de resposta (avaliação, potência e atividade); 3) com base nas médias obtidas por um grupo em cada item, em cada dimensão e na escala como um todo, podem ser construídos perfis do conceito ou da atitude; 4) escalas diferenciais semânticas oferecem medidas multidimensionais de atitudes (OSGOOD; SUCI; TANNEMBAUN, 1976).

As escalas de adjetivos bipolares geralmente subordinam-se a três dimensões básicas: avaliação (ex: bom-mau); potência (ex: forte-fraco) e atividade (ex: rápido-lento) e isso possibilita comparar as atitudes. A primeira escala para avaliar atitudes de adultos em relação à velhice de que se tem notícia veio à luz em 1944. Era de natureza dicotômica, e servia para avaliar expectativas de pais idosos sobre responsabilidade filial. Em 1952 e em 1953, foram publicadas outras duas escalas dicotômicas, para avaliar o ponto de vista de empregadores e entrevistadores em relação a trabalhadores idosos, à época, pessoas de 45 anos e mais.

Nos anos 1960 e 1970, essas escalas foram sucessivamente modificadas para uso em estudos em que se comparavam atributos de trabalhadores idosos e não idosos, idosos e estudantes universitários e adultos de várias faixas de idade. Kogan (1961) e Neugarten; Havigurst e Tobin (1961) publicaram outros instrumentos, em formato 
Likert, em que se solicita aos respondentes que analisem afirmações e que atribuam pesos ou graus de concordância à sua opinião em relação a elas. $\mathrm{O}$ primeiro produziu um instrumento contendo itens positivos e negativos extraídos da literatura sobre preconceitos em relação à velhice. Os outros autores construíram uma escala tipo Likert para avaliar satisfação de adultos mais velhos em relação à velhice cobrindo as dimensões envolvimento e apatia, resolutividade e fortaleza, congruência entre metas pretendidas e estados de humor.

Sheppard (1980) fez uma adaptação dessa escala, contendo 20 itens, e transformou-a em medida de avaliação de atitudes em relação à velhice pessoal, com os fatores "expectativa em relação à atividade" (fator 1), "sentimentos em relação à velhice" (fator 2), "expectativas em relação à satisfação" (fator 3) e "ansiedade em relação à morte" (fator 4). Neri (1986) fez uma adaptação cultural desse instrumento para o português, que revelou uma estrutura fatorial de quatro fatores assim denominados: "é possível ser feliz na velhice" (fator 1), "a velhice prenuncia dependência, morte e solidão" (fator 2), "é melhor morrer cedo do que sentir a angústia e a solidão da velhice" (fator 3), e "a velhice pode propiciar sentimentos de integridade" (fator 4).

Sarkisian e colaboradores

construíram uma escala com 38 itens e sete fatores na versão de 2001 e de 12 itens e três fatores na versão de 2005, para medida de expectativas em relação à velhice em idosos. Consideravam expectativas como elementos predisponentes a comportamentos de saúde. Seus resultados não são dados em termos de negativos x positivos, ou de certos x errados. Em vez disso, pontuações baixas são indicativas de expectativas de declínio e pontuações altas como sinais de expectativas de manutenção e melhoria do funcionamento físico e mental.

$\mathrm{O}$ primeiro instrumento nos moldes do diferencial semântico para avaliar velhice foi construído por Rosencrantz e McNevin (1969). Seus atributos representam estereótipos positivos e negativos e servem para avaliar adultos e idosos. A análise fatorial dos dados da aplicação do instrumento a 287 sujeitos entre 17 e 21 anos de idade revelou os seguintes fatores: instrumentalidade - ineficácia, autonomia dependência, e aceitabilidade - rejeição social. Posteriormente, outros autores derivaram a dimensão integridade - não integridade (do ego)

No Brasil, com base em pesquisa de campo e em análise da literatura especializada, Neri (1991) construiu uma escala diferencial semântica com 40 itens bipolares e aplicou-a a uma amostra de 4.300 brasileiros não idosos (14 a 45 anos). Com base em análises fatoriais, derivou em estrutura de cinco fatores que em parte replicam as de Rosencrantz e McNevin (1969): instrumentalidade-ineficácia, autonomia-dependência, valorizaçãodesvalorização, desejabilidade-rejeição e adaptaçãodesadaptação. Posteriormente, essa escala foi modificada com base em pesquisa empírica e traduziu-se num instrumento de 30 itens agrupados nos fatores: cognição, agência, relacionamento social e persona (NERI, 1995).

Uma forma interessante de avaliar atitudes em relação a idosos é usar diferentes conceitos de forma comparativa. Netz e Ben-Sira (1993) aplicaram uma escala diferencial semântica em famílias de três gerações em Israel, avaliando os conceitos "o idoso", "o jovem", "o adulto" e "uma pessoa ideal", enquanto Neri (1991) comparou os conceitos "o idoso é" e "quando eu for velho eu serei" em amostra de brasileiros não idosos (13 a 45 anos). Em ambas as investigações, os conceitos relativos a figuras idealizadas corresponderam a atitudes mais positivas do que os demais conceitos, em todos os grupos de idade. No estudo de Israel, o conceito "o idoso" foi avaliado de forma mais positiva pelos idosos do que pelos não idosos.

A escala diferencial semântica para crianças mais citada na literatura apareceu em 1976 e foi denominada Children's Attitudes Toward the Elderly (CATE). Em busca realizada na base de dados Ageline, cobrindo o período 1976-2008, foram localizados nove artigos relatando o uso desse instrumento, de um total de 26 indexados pela palavra-chave children's atitudes toward the elderly. Na base Psyinfo, entre 1976 e 2008, foram localizados mais dois estudos usando o CATE, porém sob a rubrica attitudes toward aging.

Conforme Middlecamp e Gross (2002), a CATE é usada com crianças de 3 a 12 anos e tem quatro subtestes: uma escala diferencial semântica, uma tarefa de associação de palavras, uma série de figuras e um subteste de conceitos de idade. Sua confiabilidade foi estabelecida por Seefeldt (1987). $\mathrm{Na}$ escala diferencial semântica, as crianças são convidadas a apontar seus conceitos de pessoa idosa e de pessoa jovem a partir de um conjunto de 10 itens contendo adjetivos bipolares (por exemplo, em tradução livre: feia-bonita, certa-errada, feliz-triste, boa-má). A tarefa consiste em examinar fotografias contendo o rosto de um homem jovem e de um 
homem idoso e dizer em que medida elas são comparáveis aos descritores representados pelos pares de adjetivos. As respostas podem variar de 1 a 6 , sendo que 1 significa a atitude mais negativa e 6 a mais positiva.

Foram localizadas mais duas escalas diferenciais semânticas utilizáveis com crianças, mas com uso menos frequente do que a CATE. Uma é a Semantic Differential Measuring Intergenerational Attitudes, instrumento utilizado por Pinquart e Sörensen (2000) e composto por 10 itens com adjetivos como hábil/desajeitado; dependente/independente; alegre/triste, com seis níveis de intensidade. A outra é a Semantic Differential composta por 17 itens com adjetivos tais como sábio/bobo; rápido/lento; bom/mau; alegre/triste; valorizado/desvalorizado; saudável/doente.

Além das escalas diferenciais semânticas, foram encontrados outros instrumentos estruturados para crianças. Um deles é a Social Attitude Scale of Ageist Prejudice - SASAP - citada por Isaacs e Bearison (1986), mas não encontrada como artigo de periódico, permitindo supor que, ou foi publicada e é comercializada como teste, ou é outro tipo de publicação diferente de artigo de periódico (por exemplo, tese ou dissertação, ou capítulo de livro). Outros exemplos são a escala tipo Likert Kogan's Attitudes Toward Old Persons, adaptada por Klein, Council e McGuire (2005); os questionários de Marks, Newman e Onawola (1985), Chowdhary e outros. (2000); o Attitude Perception Questionnaire, o questionário de percepção de atitudes utilizado por Nishi-Strattner e Myers (1983), a Children's Assessment of Old People Scale (CARSTENSEN; MANSON; CALDWELL, 1982); a Children's Views On Ageing (CVOA); e as tarefas de completar sentenças (LICHTENSTEIN et al., 2003).

Medidas de atitudes em relação aos idosos, à velhice e ao envelhecimento têm sido foco de estudos desde a metade do século XX, quando Simmons examinou dados etnográficos de 71 sociedades não industrializadas, obtidos por meio da análise de registros do século XIX, onde o pesquisador buscou informação sobre o status e o tratamento do idoso. Nos anos de 1952 e 1953, Tuckman \& Lorge levantaram atitudes em relação a idosos institucionalizados em estudantes de nível secundário e superior e em profissionais. Documentaram variabilidade de atitudes e realçaram os aspectos negativos. Desde então, as pesquisas avançaram bastante. Nos primeiros 25 anos, elas focalizaram comparações entre sociedades e grupos sociais, bem como realizaram comparações por critérios de gênero e idade (NERI, 1991). A partir dos anos 1970, ganhou corpo a investigação de atitudes baseada no conceito de discriminação etária ou ageism, seus determinantes e formas de manifestação em sociedades. Chowdhary e colaboradores (2000) alertaram os educadores e pesquisadores quanto à necessidade de incluir controle das variáveis de modo que os resultados advindos dos projetos educativos de intervenção possam ser mais confiáveis. No entanto, investigações de natureza experimental envolvendo atitudes de crianças em relação a idosos são raras na literatura científica brasileira.

\section{Desenvolvimento}

Planejar um estudo envolvendo avaliação e mudança de atitudes em relação a idosos entre crianças de 7 a 10 anos implicou em desenvolver um instrumento de medida de atitudes e um projeto educacional visando à mudança de atitudes. No caso do instrumento de medida, a opção foi pela elaboração de uma escala nos moldes do diferencial semântico, tendo em vista a disponibilidade de um instrumento brasileiro do mesmo tipo, testado com indivíduos de 13 a 45 anos, instrumento esse baseado em teoria e em análise estatística (NERI, 1991). Além disso, pareceu teórica e empiricamente atraente a ideia de adaptá-la para crianças em idade escolar, já que parece haver uma lacuna na base de conhecimentos sobre atitudes infantis em relação a idosos no Brasil.

Assim sendo, foi realizado um estudo de caráter metodológico para cobrir a questão da construção de uma escala tipicamente brasileira. Procuramos ser fiéis a uma das recomendações centrais de Osgood, Suci e Tannembaum (1976), segundo a qual os adjetivos bipolares devem ser semanticamente adaptados aos respondentes. Isto significa que devem ser aqueles que vigoram na sua comunidade verbal. A tarefa central deste estudo foi levantar significados de velhice entre as crianças e em representá-los da forma mais confiável possível num instrumento estruturado nos moldes de uma escala diferencial semântica, de uma forma facilmente inteligível para elas. Acreditar que as atitudes exercem um papel orientador sobre os comportamentos do indivíduo em relação aos outros, ao autoconhecimento e à autoavaliação é importante motivo para a realização de estudos sobre as atitudes em relação à velhice e, portanto, tão igualmente necessário se faz investigar as 
atitudes de crianças em relação aos idosos (NERI, 1997).

A seguir, descrever-se-á o processo de construção de uma escala para avaliação de atitudes de crianças em relação a idosos. Para isso, o relato do estudo está organizado em quatro partes: objetivo geral, objetivos específicos, método e considerações finais.

\section{Objetivo geral}

Adaptar um instrumento nos moldes da escala diferencial semântica, construída originalmente para adultos, para crianças de 7 a 10 anos de idade e investigar indicadores de confiabilidade interna para essa versão.

Objetivos específicos

1. Identificar significados associados a ser idoso segundo crianças de 7 a 10 anos.

2. Testar a compreensibilidade de instrumentos escalares construídos com base nesses significados e na opinião de especialistas, junto a crianças da mesma idade.

3. Avaliar a consistência interna da versão final da escala construída, segundo a lógica diferencial semântica, e testes estatísticos.

Método

O instrumento tomado como ponto de partida para a construção de um instrumento para crianças de 7 a 10 anos foi a Escala Neri para Avaliação de Atitudes em Relação à Velhice (NERI, 1991, 1997; NERI; CACHIONI; RESENDE, 2002). Trata-se de escala diferencial semântica composta por 30 pares de atributos bipolares. A estrutura fatorial desse instrumento compreende quatro fatores:

FAtOR 1. CoGNIÇÃo. Contém 10 itens relativos à capacidade de processamento da informação e de solução de problemas, com reflexo sobre a adaptação social dos idosos. São eles: sábiotolo; claro-confuso; preciso-impreciso; concentradodistraído, rápido-lento, flexível-rígido, criativoconvencional, persistente-inconstante, alertaembotado e seguro-inseguro.

FATOR 2. AGÊNCIA. São seis itens referentes à autonomia e instrumentalidade: entusiasmado-deprimido; saudável-doentio, ativoinativo, esperançoso-desesperado, independentedependente e produtivo-improdutivo.

FATOR 3. RELACIONAMENTO SOCIAL. Os sete itens desse fator cobrem aspectos afetivo- emocionais que se refletem na interação social entre o idoso e os outros: construtivo-destrutivo, bemhumorado-mal-humorado, confiante-desconfiado, cordial-hostil, interessado pelas pessoasdesinteressado pelas pessoas, generoso-mesquinho e condescendente-crítico.

FATOR 4. PERSONA. Este fator diz respeito à imagem social dos idosos e inclui sete pares de atributos em oposição: aceito-rejeitado, integradoisolado, atualizado-ultrapassado, valorizadodesvalorizado, agradável-desagradável, progressista-retrógrado e sociável-introvertido.

\section{FASES DO PROCEDIMENTO}

Foram nove as fases do procedimento de construção do instrumento para crianças. Ele envolveu estratégias qualitativas e quantitativas e diversas fontes de informação.

$1^{a}$ fase: Levantamento de significados de ser idoso junto a crianças de $1^{\mathrm{a}}$ e $2^{\mathrm{a}}$ série

$2^{\mathrm{a}}$ fase: Cotejo dos significados levantados com os constantes da Escala Neri

$3^{a}$ fase: Construção de um protótipo de escala

$4^{\mathrm{a}}$ fase: Teste de compreensibilidade junto a dois grupos independentes de crianças

$5^{\text {a }}$ fase: Reformulação da escala com base nos resultados do teste de compreensibilidade

$6^{\mathbf{a}}$ fase: Análise dos itens por duas especialistas em linguística e sugestões de substituição por sinônimos

$7^{\text {a }}$ fase: Levantamento de palavras utilizadas por crianças em idade escolar para expressar os significados de ser idoso constantes do instrumento analisado pelas linguistas

$8^{a}$ fase: Construção de nova versão da escala com base nos adjetivos mais utilizados pelas crianças para expressar os significados de ser idoso constantes do instrumento analisado pelas linguistas

$9^{a}$ fase: Análise da consistência interna da escala para medida de atitudes de crianças em relação à velhice.

$1^{a}$ a $4^{a}$ fase, correspondente à produção da primeira versão de um instrumento baseado em significados correntes entre crianças de $1^{a}$ a $4^{a}$ séries. Participaram da $1^{\text {a }}$ fase, 63 crianças entre 7 e 8 anos e 126 crianças entre 9 e 10 anos de idade. Em ambiente de sala de aula, numa sessão de 50 minutos de duração em média, a pesquisadora solicitou que as crianças de $1^{\mathrm{a}}$ a $2^{\mathrm{a}}$ série explicassem oralmente "O que é ser idoso" e que as da $3^{\mathrm{a}}$ e da $4^{\mathrm{a}}$ séries produzissem pequenos textos sobre o mesmo 
tema. As respostas foram anotadas pela pesquisadora, enquanto as crianças falavam ou liam suas produções e ao longo do debate que se instalou nas classes. Depois, fora da sala de aula, a pesquisadora realizou uma análise de conteúdo desse material verbal, buscando por termos que preenchessem os critérios da Escala Neri ( $2^{\mathrm{a}}$ fase). Os atributos foram listados conforme aparecem no Anexo 2 e com eles foi criada uma versão preliminar da escala, que continha os itens citados pelas crianças e seus antônimos, conforme a lógica da Escala Neri. Parte desses antônimos foram ditos pelas crianças e parte foram introduzidos pela pesquisadora respeitando a intenção subjacente a seus depoimentos.

Essa primeira versão recebeu o nome de Inventário Todaro (TODARO; COSTA, 2004). Ela foi aplicada a dois grupos independentes de 50 crianças cada um, perfazendo um total de 100 respondentes divididos entre 49 meninas e 51 meninos. As pesquisas foram localizadas em Atibaia (cidade do interior de São Paulo) e Uberlândia (cidade do interior de Minas Gerais). Os dois grupos obedeceram alguns critérios básicos de seleção como: terem idade semelhante (7 a 10 anos), pertencerem a escolas públicas, estarem cursando a segunda série do Ensino Fundamental e a participação espontânea na atividade consentida previamente pelos responsáveis. Os dados foram coletados em situação de grupo, em ambiente de sala de aula, gastando algo em torno de 30 minutos com cada grupo. Com o objetivo de descrever e comparar as opiniões dos dois grupos de crianças pôde-se ao final do estudo, perceber que as crianças apresentaram respostas semelhantes para a maioria dos adjetivos. Apenas nos itens desconfiadosconfiantes; saudáveis-doentes e seguros-inseguros as respostas apresentaram diferenças significativas quando da comparação feita entre os grupos. As dúvidas e comentários das crianças durante a aplicação-piloto em termos da compreensibilidade do instrumento foram elencados pelas pesquisadoras: "Sabido é que nem inteligente?"; "Sabido é sábio, né?" "O que que é confiante?"; "Minha mãe reclama que meu avô é pão-duro! Pode escrever aqui?"; "Minha avó é confusa... Uma hora tá falando uma coisa e depois mistura tudo... Posso por isto?". O que resultou desta aplicação foi acatar a sugestão dada pelas próprias crianças investigadas de se utilizar escalas de três pontos e não dicotômicas, que foi adotada posteriormente.

A versão inicial aparece no Quadro 1 e trazia a seguinte comanda: "Estamos interessados em saber o que as crianças pensam sobre os velhos. Você encontrará a seguir uma escala de 13 itens. Cada item contém duas palavras opostas. Marque um $\mathrm{X}$ em apenas um dos dois parênteses de cada item".

Quadro 1. Inventário Todaro para avaliação de atitudes de crianças em relação aos idosos

\begin{tabular}{|ll|}
\hline & OS VELHOS SÃO: \\
SABIDOS ( ) & BOBOS ( ) \\
BEM-HUMORADOS ( ) & MAL-HUMORADOS ( ) \\
DESCONFIADOS ( ) & CONFIANTES ( ) \\
ALEGRES ( ) & TRISTES ( ) \\
LEGAIS ( ) & CHATOS ( ) \\
DOENTES ( ) & SAUDÁVEIS ( ) \\
ATIVOS ( ) & PARADOS ( ) \\
DEPENDENTES ( ) & INDEPENDENTES ( ) \\
CLAROS ( ) & CONFUSOS ( ) \\
INSEGUROS ( ) & SEGUROS ( ) \\
RÁPIDOS ( ) & LENTOS ( ) \\
DISTRAIIDOS ( ) & ATENTOS ( ) \\
CRIATIVOS ( ) & SEM CRIATIVIDADE ( ) \\
\hline
\end{tabular}

Fonte: Organização da autora

Os itens sabidos-bobos, claros-confusos, inseguros-seguros, rápidos-lentos, criativos-sem criatividade e distraídos-atentos dizem respeito ao domínio cognitivo. Os pares alegres-tristes, doentes-saudáveis, ativos-parados, dependentesindependentes referem-se ao domínio agência. Os atributos bem-humorados-mal-humorados $e$ desconfiados-confiantes refletem relacionamento 
social. O item legais-chatos refere-se ao domínio persona.

$5^{a}$ fase, correspondente à análise por duas linguistas. Representando um outro momento do procedimento de adaptação, a Escala Todaro e a Escala Neri foram analisadas por duas especialistas em Linguística que apresentaram sugestões de ordem semântica e cultural, tentando encontrar adjetivos mais próximos aos utilizados na Escala Neri e, ao mesmo tempo, mais típicos do universo infantil. Alguns adjetivos foram considerados de difícil entendimento para crianças de 7 a 10 anos, como: tolo, destrutivo, construtivo, rejeitado, entusiasmado, integrado, ultrapassado, atualizado, desvalorizado, cordial, hostil, inativo, introvertido, sociável, esperançoso, mesquinho, generoso, produtivo, improdutivo, progressista, retrógrado, condescendente, preciso, impreciso, concentrado, flexivel, rígido, convencional, persistente, inconstante, alerta e embotado. A sugestão dada foi de que os termos fossem substituídos por sinônimos ou excluídos.

$6^{a}$ fase. As especialistas disseram que um instrumento apropriado para crianças deveria ser mais curto e conter adjetivos que fizessem parte do universo de vocábulos desta faixa etária (entre 7 e 10 anos). Sugeriram ainda que fosse testado o entendimento destes termos e que se mantivesse mesma proporção de itens da escala Neri por categoria: Cognição: 6 pares de adjetivos $=34 \%$; Agência: 2 pares $=20 \%$; Relacionamento Social: 3 pares $=23 \%$ e Persona: 3 pares $=23 \%$. Indicaram também que a escala Todaro deveria seguir a mesma lógica da comanda da escala Neri: "O idoso é", substituindo a expressão "os velhos são" por "Os idosos são", para não gerar viés. Além da orientação de utilizar letras do tipo "bastão", ou seja, maiúsculas, levando em consideração a etapa de alfabetização.

$7^{a}$ fase, representada por novo levantamento de atributos junto às crianças. Considerando as recomendações acima descritas, planejou-se a $7^{\text {a }}$ fase do procedimento de adaptação que consistiu em:

1) Desmembrar cada item em dois (positivo e negativo).

2) Escrever vinhetas, uma para cada adjetivo, contendo descrições de um indivíduo que correspondesse ao atributo, sem porém, usar o adjetivo. Cada vinheta continha ao final uma frase para completar: "Essa pessoa é ,"

3) Utilizar observadores independentes na busca de concordância entre os significados (acordo construído entre juízes).

4) Submeter as vinhetas às crianças.

5) Analisar os significados atribuídos pelas crianças aos adjetivos utilizados para verificar correspondência entre eles.

Passou-se depois à confirmação do entendimento das crianças em relação ao significado de alguns termos. Para tanto, foi construída uma outra versão, com os termos utilizados pelas crianças.

$8^{a}$ fase. $\mathrm{O}$ instrumento que aparece no quadro 2 é o resultado final do processo de adaptação:

Quadro 2. Versão final da Escala Todaro para Avaliação de Atitudes de Crianças em Relação a Idosos

\begin{tabular}{|c|c|c|}
\hline SÁBIOS & $\begin{array}{l}\text { OS IDOSOS SÃO: } \\
\text { 1---1--1 }\end{array}$ & BOBOS \\
\hline & $\begin{array}{lll}1 & 2 & 3\end{array}$ & \\
\hline BEM-HUMORADOS & 1-------1-------1 & MAL-HUMORADOS \\
\hline COLOCADOS DE LADO & $\begin{array}{lcr}1 & 2 & 3 \\
1------1------1\end{array}$ & ACEITOS \\
\hline & $\begin{array}{lll}1 & 2 & 3\end{array}$ & \\
\hline ALEGRES & $\begin{array}{lrr}1------1------1 \\
1 & 2 & 3\end{array}$ & TRISTES \\
\hline VALORIZADOS & $\begin{array}{llr}1-----1------1 \\
1 & 2 & 3\end{array}$ & MALTRATADOS \\
\hline LEGAIS & $\begin{array}{lll}1------1------1 \\
1 & 2 & 3\end{array}$ & CHATOS \\
\hline DOENTES & 1-------1--------1 & SAUDÁVEIS \\
\hline
\end{tabular}




\begin{tabular}{|c|c|c|}
\hline BONZINHOS & $\begin{array}{rrr}1 & 2 & 3 \\
1- & -1-\end{array}$ & BRAVOS \\
\hline PÃES-DUROS & $\begin{array}{lrr}1 & 2 & 3 \\
1-----1-----1\end{array}$ & MÃOS-ABERTAS \\
\hline CLAROS & $\begin{array}{lrr}1 & 2 & 3 \\
1-----1-----1\end{array}$ & CONFUSOS \\
\hline & $\begin{array}{lll}1 & 2 & 3\end{array}$ & \\
\hline INSEGUROS & $\begin{array}{lll}1-----1-----1 \\
1 & 2 & 3\end{array}$ & SEGUROS \\
\hline ATENTOS & $\begin{array}{llr}1- & --1- \\
1 & 2 & 3\end{array}$ & DISTRAÍDOS \\
\hline LENTOS & 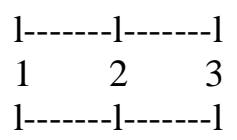 & $\begin{array}{l}\text { RÁPIDOS } \\
\text { SEM CRIATIVIDADE }\end{array}$ \\
\hline CRIATIVOS & $\begin{array}{lll}1 & 2 & 3\end{array}$ & \\
\hline
\end{tabular}

Fonte: Todaro (2008)

Os seis itens: sábios-bobos, clarosconfusos, inseguros-seguros, lentos-rápidos, criativos-sem criatividade, atentos-distraídos dizem respeito ao domínio cognitivo. Os dois pares alegres-tristes e doentes-saudáveis referem-se ao domínio agência. Os três itens bem-humorados-malhumorados, colocados de lado-aceitos, valorizadosmaltratados cobrem aspectos do domínio relacionamento social. Os três pares legais-chatos, bonzinhos-bravos, pães-duros-mãos-abertas referem-se à persona.

$9^{a}$ fase. O último passo consistiu em levantar indicadores de confiabilidade interna para a Escala Todaro. Foi calculado o índice $\alpha$ de Cronbach para a escala como um todo, em duas ocasiões de medida separadas por cinco semanas, durante as quais os 248 participantes das duas medidas foram submetidas a uma intervenção educacional visando suas atitudes em relação aos idosos. As crianças tinham de 7 a 10 anos de idade e estavam distribuídas de forma equiitativa pelas quatro séries iniciais do Ensino Fundamental. Dentre elas, 130 eram meninas. Não foram observadas diferenças estatisticamente significantes quanto à distribuição por gênero e idade em cada uma das quatro séries escolares. As medidas de consistência interna da Escala Todaro resultaram em índices satisfatórios, indicando que seus itens provavelmente são referentes a um mesmo construto.

\section{Considerações finais}

Para que se possa avaliar o efeito de um projeto educativo que visa à mudança de atitudes é necessário ter instrumentos adequados. O procedimento, aqui descrito, se mostrou fiel à prescrição de Osgood (1976), ouvindo a comunidade verbal para a qual o instrumento de avaliação se dirige. Esta fidelidade também se revelou na adoção de questões relativas à compreensão dos adjetivos bipolares, pois era necessário adequá-los à idade e à cultura dos respondentes. Para tanto, foram ouvidas as próprias crianças e duas especialistas em linguística. Alguns adjetivos adotados são compartilhados por escalas construídas fora do Brasil, tais como a CATE Children Attitudes Toward Elderly, a Semantic Differential Measuring Intergenerational Attitudes e a escala construída por Eisendorf e Altrocchi em 1961 e adaptada por Lynott e Merola em 2007.

Os indicadores de confiabilidade interna para essa versão demonstraram índices satisfatórios. $\mathrm{O}$ cálculo do coeficiente alfa $^{2}$ apresentou valores indicadores de boa consistência interna. Há vantagens e limitações no presente estudo. As vantagens dizem respeito a ser um instrumento construído a partir da linguagem de crianças brasileiras, e não adaptado de um congênere estrangeiro. As limitações estão associadas ao fato de ser um estudo preliminar, ainda sem indicadores adicionais de validade interna, de critério ou de construção, ao fato de os itens bipolares terem apenas três intensidades, quando o ideal é uma possibilidade de conferir maior refinamento às respostas individuais e maior variabilidade às respostas dos grupos.

No cômputo geral, a construção da escala Todaro teve um saldo positivo quando usada para compor a pesquisa de doutorado "Desenvolvimento e avaliação de um programa de leitura visando a mudança de atitudes de crianças em relação a 
idosos". Mesmo assim, merece sugestões para investigações futuras: ver se o instrumento funciona para crianças mais velhas; comparar crianças mais velhas e mais novas; adaptar a escala com mais intensidades e trabalhar com grandes amostras (TODARO, 2008).

Na sociedade brasileira contemporânea, que vivencia o desafio do envelhecimento populacional, estudos que estabelecem uma relação entre educação e gerontologia são importantes para apontar novos rumos para o combate ao preconceito em relação às pessoas idosas. É na perspectiva de um novo paradigma educacional, de uma Pedagogia Progressista, que prevê a transformação social por meio da educação, que as atitudes de crianças precisam ser verificadas para que ações educativas possam ser planejadas para impactar na formação integral de pessoas cada vez mais humanas.

\section{Notas}

1 Este artigo é fruto da tese de doutorado da autora.

2 O coeficiente alfa de Cronbach mede a correlação entre respostas em um questionário através da análise das respostas dadas pelos respondentes, apresentando uma correlação média entre as perguntas. É calculado a partir da variância dos itens individuais e da soma dos itens de cada avaliador de todos os itens de um questionário que utilizem a mesma escala de medição.

\section{Referências}

CARSTENSEN, L.; MANSON, S. E.; CALDWELL, E. C. Children's attitudes toward the elderly: an intergenerational technique for change. Educational Gerontology, v. 8, p. 291-301, 1982.

CHOWDHARY, U., SCHULTZ, C. M., HASSELRIIS, P., KUJATH, H. A., PENN, D.; HENSON, S. Intergenerating activities and aging appreciation of elementary school children. Educational Gerontology, v. 26, p. 541-564, 2000.

EAGLY, A H. \& CHAIKEN, S. Psychology of Attitudes. New York: Harcourt Brace \& Company. 1993.

ENGELMANN, Arno. Os Estados Subjetivos: uma tentativa de classificação de seus relatos verbais. São Paulo: Ática. 1978.
ISAACS, L. \& BEARISON, D. The development of children's prejudice against the aged. International Journal of Aging and Human Development, v. 23, p. 175- 194, 1986.

KLEIN, D. A., COUNCIL, K. J.; MCGUIRE, S. L. Education to promote positive attitudes about aging. Educational Gerontology, v. 31, n. 8, p. 591-601, 2005.

KOGAN, N. Attitudes toward old people: the development of a scale and an examination of correlates. Journal of Abnormal and Social Psychology. v. 62, p. 44-54, 1961.

LICHTENSTEIN, M. J.; et all. Sentence completion to assess children's views about aging. The Gerontologist.v. 43, n. 6, p. 839-848, 2003.

LIKERT, R. Una tecnica para medir actitudes. In: SUMMERS, Gene F. Medicion de Actitudes. Archives of Psychology, 140, p. 182-193, 1976.

LUSZCZ, M. A. An attitudinal assessment of perceived intergenerational affinities linking adolescence and old age. International Journal of Behavioral Development, v. 6, p. 221-231, 1976.

LYNOTT, P. P.; MEROLA, P. R. Improving the attitudes of 4th graders toward older people through a multidimensional intergenerational program. Educational Gerontology, v. 33, 1, p. 63-74, 2007.

MARKS, R., NEWMAN, S.; ONAWOLA, R. Latency aged children's views of aging. Educational Gerontology. v. 11, p. 89-99, 1985.

MIDDLECAMP, M.; GROSS, D. Intergenerational daycare and preschoolers' attitudes about aging. Educational Gerontology, v. 28, p. 271-288, 2002.

NERI, A. L. O inventário Sheppard para medida de atitudes em relação à velhice e sua adaptação para o português. Estudos de Psicologia, v. 3, n.12, p. 23$42,1986$.

NERI, A. L. Envelhecer num país de jovens: significados de velho e velhice segundo brasileiros não idosos. Campinas: UNICAMP, 1991.

NERI, A. L. Atitudes e crenças em relação à velhice: o que pensa o pessoal do SENAC. Relatório técnico. São Paulo: SENAC, 1995. 
NERI, A. L. Atitudes em relação à velhice: evidências de pesquisas no Brasil. Gerontologia, v. 5, n. 3, p. 130-139, 1997.

NERI, A. L.; CACHIONI, M.; RESENDE, M. C. de. Atitudes em relação à velhice. In: Tratado de Geriatria e Gerontologia. Rio de Janeiro: Guanabara-Koogan, 2002.

NETZ, Y.; BEN-SIRA, D. Attitudes of young people, adults and older adults from three generation families toward the concepts "ideal person", "youth", "adult" and "old person". Educational Gerontology. v. 19, 7, p. 607-621, 1993.

NEUGARTEN, B. L.; HAVIGHURST, R. J.; TOBIN, S. S. The measurement of life satisfaction. Journal of Gerontology. v. 16, p. 134-143, 1961.

NISHI-STRATTNER, M.; MYERS, J. E. Attitudes toward the elderly: an intergenerational examination. Educational Gerontology, v. 8, p. 389397, 1983.

OSGOOD, C. E., SUCI G. J.; TANNEMBAUM, P. H. Medicion de actitudes. In: SUMMERS, G. F. Medicion de Actitudes. México: Trilhas, 1976.

PASQUALI, L. Princípios de elaboração de escalas psicológicas. In: GORENSTEIN, C., ANDRADE, L. H. S. G.; ZUARDI, A. W. Escalas de Avaliação Clínica em Psiquiatria e Psicofarmacologia. São Paulo: Lemos Editorial, 1999.

PINQUART, M.; SÖRENSEN, S. Changes in attitudes among children and elderly adults in intergenerational group work. Educational Gerontology, v. 26, p. 523-540, 2000.

ROSENCRANTZ, H. A. \& MCNEVIN, T. E. A factor analysis of attitudes toward the aged. The Gerontologist, v. 9, p. 55-59, 1969.

SARKISIAN, C.A.; HAYS, R. D., BERRY, S.; MANGIONE, C. M. Development, reliability and validity of the Expectations Regarding Aging (ERA- 38) Survey. The Gerontologist. v. 42, p. 534$542,2002$.

SEEFELDT, C. The effects of preschoolers visits to a nursery home. The Gerontologist. v. 27, p. 228232, 1987.

SHEPPARD, A. Attitudes toward aging: analysis of an Attitude Inventory for Younger Adults. In: The J. S. A. S. Catalog of Selected Documents in Psychology. v. 11, n. 3, 1980.

THURSTONE, L. L. Las actitudes pueden medirse. In: SUMMERS G. F. Medición de Actitudes. Mexico: Trillas, 1976. p. 157-173.

TODARO, M. A. e COSTA, G. A. Crianças e velhos: a imagem do outro. Aterceiraidade. v. 15, $\mathrm{n}$. 29, p.28-47, 2004.

TODARO, M. A. Desenvolvimento e avaliação de um programa de leitura visando a mudança de atitudes de crianças em relação a idosos. 2008. 166p. Tese (Doutorado em Educação). Faculdade de Educação. Universidade Estadual de Campinas.

\section{Sobre a autora}

Mônica de Ávila Todaro é pedagoga, mestre em Gerontologia e doutora em Educação pela Universidade Estadual de Campinas - UNICAMP. Professora adjunta do Departamento de Ciências da Educação da Universidade Federal de São João del Rei - MG. Líder do grupo de pesquisa "Pedagogia do corpo consciente" (CnPq).

Recebido em abril de 2016.

Aprovado em agosto de 2016. 